\title{
SOCIOLOGIA(S) EM ESCALA INDIVIDUAL
}

\section{SOCIOLOGY(IES) ON AN INDIVIDUAL SCALE}

\author{
Giovanni Boaes (UFPB)* \\ Sheila Borges de Oliveira (UFPE) ${ }^{* *}$ \\ Rodrigo Vieira de Assis (UERJ) ${ }^{* * *}$
}

As sociologias do indivíduo ${ }^{1}$ são um capítulo da Sociologia que se abre neste século XXI com mais liberdade e autoridade depois de permanecer entreaberto ou como leitura marginal ao longo do século de suas origens, o XIX, e o do seu desenvolvimento, o XX. Apesar de "o indivíduo" não ser um objeto novo nas teorias sociais, como observa Martuccelli (2007) - sendo ele "o elemento mais velho que pode existir" nessas teorias -, a enfatizada lição dos clássicos, especialmente Durkheim, de que o objeto da sociologia deveria se fundar em patamares ontológicos e empíricos não redutíveis ao indivíduo vingou, e quanto mais forte ficava o estatuto da sociologia como uma ciência da sociedade, mais o social e o individual foram se afastando. Predominou, até mais ou menos os anos de 1950, diz Martuccelli (2007), na interpretação sociológica, a "lógica descendente", que vai da sociedade ao indivíduo, na qual o indivíduo é substituído sem intermediações pela ideia geral de "posição social" ou seu derivado, o "personagem social". Assim, conhecendo a ideia de sociedade, a ancoragem e a posição do ator na sociedade, seria possível compreender uma grande quantidade de facetas do ator individual, sem necessariamente se preocupar com a singularidade desse ator.

Todavia, as reviravoltas teórico-metodológicas e as controvérsias internas que marcaram as últimas décadas do século XX, no campo sociológico, parecem apontar para outra leitura da disciplina que abre caminho a uma sensibilidade redirecionada quanto ao foco dado aos fenômenos sociais. Registra-se um "retorno do sujeito", como percebe Gaulejac (2004/2005), que implica a "morte do personagem social", para usar a metáfora cunhada por Martuccelli (2007). Dito de outro modo, no réquiem do personagem social, o sujeito vai retornando.

\footnotetext{
*Doutor em Sociologia, UNESP/Brasil. Professor do Departamento de Ciências Sociais da Universidade Federal da Paraíba/Brasil. E-mail: giboaes@gmail.com

${ }^{* *}$ Doutora em Sociologia, UFPE/Brasil. Professora do Núcleo de Design e Comunicação do Centro Acadêmico do Agreste, da Universidade Federal de Pernambuco (UFPE)/Brasil. E-mail: sheilaborges12@gmail.com

${ }^{* * *}$ Doutorando em Sociologia, Instituto de Estudos Sociais e Políticos da Universidade do Estado do Rio de Janeiro (IESP-UERJ)/Brasil. Professor Substituto do Departamento de Ciências Sociais da UFRPE/Brasil. E-mail: rvassis@ outlook.com

1 Optamos por colocar o plural em evidência, tanto para a sociologia em escala individual quanto para a sociologia do indivíduo, por julgarmos que não se trata de um conjunto homogêneo de abordagens, apesar de compartilharem princípios gerais. O "S" entre parênteses é um "sinal luminoso" chamando a atenção para todas as condições de possibilidade de aplicação dos conceitos.
} 
São conhecidas as contribuições das grandes teorias elaboradas por autores como Norbert Elias, Pierre Bourdieu, Anthony Giddens, Jürgen Habermas e Niklas Luhmann, no intuito de sintetizar e iluminar os imbricamentos possíveis entre a sociedade e o indivíduo, o sistema e a ação, as estruturas e as práticas. Contudo, essas grandes sínteses, com exceção talvez de Norbert Elias, ainda não conseguem se afastar completamente do modelo do "personagem social", recaindo, de modos distintos, suas ênfases da análise sobre o instituído e não sobre o instituinte (KAUFMANN, 2001)2.

$\mathrm{Na}$ contramão, aquilo que fora esquecido pelo pensamento sociológico parece insurgirse e reivindicar um lugar na teoria, na metodologia e na epistemologia, e na aurora pós-áurea da macrossociologia em que nos encontramos, não só a singularidade dos indivíduos se insinua, mas a própria noção de "indivíduo" amplia-se e torna-se mais inclusiva, a partir do momento em que os negros, as mulheres, os não ocidentais, os não heterossexuais, as crianças, os animais e até os objetos inanimados também se insurgem como "sujeitos" no pensar e fazer sociológico.

Independentemente das especificidades de cada uma das teorias que marcaram o "novo movimento teórico" ${ }^{3}$, vemos a sociologia se voltar, de maneiras diversas, para o indivíduo, visualizando-o como uma chave de acesso à realidade societária e. se quisermos continuar com a metáfora espacial de Martuccelli, podemos dizer que a "lógica descendente" tende agora a inverter-se ou complementar-se: não é simplesmente a sociedade a chave para se compreender o indivíduo, mas o contrário, o individual torna-se um dos caminhos para se compreender a sociedade, implicando, obviamente uma alteração nos próprios significados das palavras "sociedade" e "indivíduo". "Ou seja, é no nível das experiências individuais que a imaginação sociológica está se recriando" (MARTUCCELLI, 2007, p. 20).

$\mathrm{O}$ mundo em que vivemos mudou, mudando também os processos de fabricação dos indivíduos. Deste cenário, emergiu um ator plural, complexo e heterogêneo em seu interior. No bojo das transformações, fortalecem-se propostas que podem ser enquadradas sob o epíteto de sociologia(s) do indivíduo, nas quais podemos arrolar alguns autores: Jean-Claude Kaufmann, François Dubet, Claude Dubar, Danilo Martuccelli, Vincent de Gaulejac, François Dubet, Dominique Memmi, Alain Ehrenberg, Bernard Lahire, entre outros. São contribuições cuja importância fundamental está em reconhecer que o social e o individual não se separam, e que sociologia e psicologia não são disciplinas opostas, mas complementares, cujo diálogo, se bem estabelecido, pode possibilitar o desvendamento de aspectos importantes anteriormente negligenciados por ambas as áreas.

Dentro dessa seara, destacamos a chamada sociologia em escala individual. Inicialmente denominada sociologia psicológica, assumindo em seguida, outras denominações, como

2 Segundo Martuccelli (2007, p. 17), a primeira grande virada para a sociologia do indivíduo deu-se com as abordagens microssociológicas norte-americanas: o interacionismo simbólico, a sociologia fenomenológica e a etnometodologia.

3 Ver Alexander, 1987. 
sociologia disposicionalista e contextualista ou interacionismo disposicionalista. É o sociólogo francês Bernard Lahire, ${ }^{4}$ seu idealizador. Ele aparece no contexto francês como um dos herdeiros de Pierre Bourdieu, a quem promete dar prolongamentos críticos ao seu pensamento e à sua obra. Colocando Bourdieu contra Bourdieu e se apropriando de perspectivas filosóficas, literárias, psicanalíticas e sociológicas, propõe um edifício teórico robusto, cujas premissas se remetem ao foco da análise em escala individual, o que significa levar a análise para dois níveis, um interindividual e outro intraindividual.

Em sua proposta, as dicotomias ou dilemas que atravessam a sociologia (estrutura $\mathrm{x}$ ação, sociedade $\mathrm{x}$ indivíduo), podem ser reescritas pela ideia de que o que é individual é social e o que é social é individual. Dito de outro modo, o programa de pesquisa de Lahire se baseia no pressuposto de que a apreensão do social se torna mais refinada quando é captada em escala individual, na medida em que o olhar aproximado sobre os indivíduos capta as possibilidades múltiplas de singularização do social. Por isso, seu esquema teórico envolve noções como as de disposição, inclinação, propensão, hábito, tendência e pluralidade das disposições e competências incorporadas, repertórios, jogo, campo secundário, oriundas de autores tão diversos quanto Durkheim, Halbwachs, Weber, Bourdieu, Goffman, Alfred Schultz, Anselm Strauss, Pierre Naville, Wittengstein, Freud e Elias.

Lahire se identifica com a tradição disposicionalista dentro da sociologia, porém, acrescentando-lhe uma dialética que nem sempre esteve presente no pensamento de outros autores disposicionalistas. Referimo-nos à relação entre disposições e contextos, ou, para usar os termos de Lahire: o passado incorporado na forma de disposições e competências, e o presente na forma de contexto. É no jogo entre estes dois elementos que o autor encontrará a fórmula geral da ação: passado incorporado + contexto = prática. É uma fórmula que condensa princípios de uma sociologia do indivíduo, do ator plural, e que requer um enquadramento interdisciplinar, pois não se poderá estudar o indivíduo, ou o singular no formato de um "social dobrado", sem levar em consideração conhecimentos da psicologia, da psicanálise e mesmo das ciências cognitivas. Não se pode considerá-lo senão diacrônica e sincronicamente, interindividual e intraindividualmente.

Para ele, a sociologia esteve oscilando entre dois polos ao longo de sua história. Imaginamos, a partir do que Lahire nos propõe em O homem plural (2001) e Monde Pluriel (2012), que um continuum poderia surgir entre esses polos, e no qual poderíamos distribuir as várias correntes sociológicas. De um lado, colocamos o disposicionalismo, e, do outro, o "contextualismo". Autores que consideram apenas o peso do passado e desconsideram a força do presente acomodam-se no primeiro polo. Já aqueles ou aquelas que consideram apenas o presente, desconsiderando o peso do passado incorporado, acomodam-se no segundo polo.

4 Bernard Lahire é professor da École Normale Supérieure Lettres et Sciences Humaines e diretor do Grupo de Pesquisa sobre Socialização da Universidade de Lyon 2. 
Sugerimos a imagem de um continuum por nos parecer mais dinâmico, permitindo deslocamentos, sem prender um autor ou uma teoria a um dos seus extremos. Uma mesma teoria, ou um mesmo autor, pode ocupar posições diferenciadas dentro do continuum, a partir de elementos específicos da teoria. Sem pretender entrar na discussão do que essa proposição pode causar, é suficiente, neste texto de apresentação, saber como a sociologia em escala individual estaria posicionada.

No lado do disposicionalismo, Lahire coloca vários autores da tradição sociológica e da psicanálise, sendo o mais expressivo para os propósitos deste texto, Pierre Bourdieu, não por ser um tipo de disposicionalista puro, mas porque terá uma importância de partida para a obra de Lahire. No segundo polo, o melhor exemplo é dos sociólogos interacionistas, que centram a sua interpretação no presente das interações face a face, deixando de lado os esquemas de experiência incorporados nos atores na forma de disposições.

A sociologia em escala individual colocar-se-ia em uma posição intermediária entre esses dois polos, conforme podemos constatar na fórmula apresentada linhas atrás. As disposições, por si só, não podem nos dar uma explicação coerente das ações, dos pensamentos e sentimentos dos atores, como também não o podem fazer, apenas os elementos do contexto. Daí, a insistência duradoura de Lahire em mostrar que a sociologia em escala individual é uma sociologia disposicionalista-contextualista, por meio da qual o pesquisador pode reconstruir o universo social do indivíduo que analisa, considerando sempre o jogo entre o passado incorporado e o presente contextualizado. ${ }^{5}$

Dos autores disposicionalistas que mais influenciaram o pensamento de Lahire, encontramos Pierre Bourdieu, com quem procura se identificar e, ao mesmo tempo, dele se afastar. Coube a Lahire, a tarefa de submeter o edifício teórico bourdieusiano a uma robusta análise crítica. Na pena de Lahire, os principais conceitos de Bourdieu (espaço social, habitus, campo e capital) passam por substancial redefinição teórica e metodológica. Nos momentos iniciais da sociologia em escala individual, Lahire se debruçou sobre o conceito bourdieusiano de habitus, como uma gramática generativa da prática, generalizável e transponível.

O resultado deste esforço é o seu livro programático - O homem plural (LAHIRE, 2001) - que, como o próprio título indica, sustenta-se na ideia mestra da existência de um indivíduo menos "coletivo", sem deixar de ser social'. Um indivíduo produzido no interior de sociedades diferenciadas, obrigado a frequentar espaços diferenciados e a viver experiências socializadoras distintas, muitas vezes contraditórias, resultando dessa inserção pluricontextual, resumos de experiências incorporados (corporalmente) na forma de estoques de disposições.

5 “Todas as tendências para as análises unilaterais, exclusivamente contextualistas ou exclusivamente disposicionalistas, provam o quanto é difícil para as ciências humanas e sociais encontrar o equilíbrio nesta fórmula científica na análise das práticas sociais" (LAHIRE, 2010, p. 40).

6 Para acompanhar a percepção de Lahire sobre o estatuto do coletivo e do social nas interpretações sociológicas, ver o seu conhecido post-scriptum: indivíduo e sociologia, no livro A cultura dos indivíduos (LAHIRE, 2006). 
O "homem plural" é o indivíduo predominante do mundo plural. Nele, há disposições que, em parte, explicam sua maneira de pensar, agir, sentir e crer. A outra parte cabe ao contexto que, em interação com o estoque de disposições, dá rumo às ações, ao pensamento, ao sentimento e às crenças. Assim, o conceito de habitus como um sistema, generalizável e transponível, originado nas posições sociais ocupadas dentro de um campo, mostrar-se-ia incapaz de explicar os comportamentos humanos nas sociedades diferenciadas, comportamentos menos homogêneos em relação às unidades coletivas (grupos, classes sociais, família etc.), como foram em sociedades menos diferenciadas.

Uma vez esboçadas as linhas mestras da sua sociologia disposicionalista e contextualista em $O$ homem plural, Lahire leva a cabo, como ele mesmo faz questão de enfatizar ${ }^{7}$, um exercício de "sociologia experimental" para colocar à prova suas ideias. Esse empreendimento culmina com o livro Retratos sociológicos (LAHIRE, 2004), cujo mérito não se deve apenas ao teste de seus conceitos e ideias, mas à aplicação de sua metodologia, os chamados retratos sociológicos e ou biografia sociológica. Temos, nesse livro, a construção de 8 retratos, nos quais o autor, por meio da realização de longas, metódicas e cansativas entrevistas, reforça a tese do homem plural, e da pertinência de se compreender as ações a partir da relação entre o estoque de disposições do indivíduo e sua relação com o contexto.

A sociologia em escala individual, ao traçar o retrato sociológico de alguém, vai em busca das disposições, sua gênese, como se formaram, em quais contextos, sob quais influências e como se colmataram na biografia do indivíduo, em sua trajetória, como singularizam o social, como o dobram. Neste sentido, para Lahire, toda sociologia em escala individual é uma sociologia da socialização. Nela, é possível compreender, uma vez acionando os contextos, passados e presentes, como e por que agem, sentem, creem e pensam as pessoas.

Em A cultura dos indivíduos, Lahire (2006), utilizando-se de uma metodologia criativa, na qual combina técnicas quantitativas e qualitativas, avalia a homogeneidade e heterogeneidade (consonância e dissonância) de comportamentos culturais de frações de classes sociais francesas, entrecruzando sete variáveis, o que lhe permitiu criar tipos de perfis a partir do foco das escalas individuais. Ao estudar as variações intra e interindividuais desses atores, percebe que há variações significativas no gosto, no consumo e nas práticas culturais em todos os fragmentos de classe estudados, o que soa como resposta direta aos resultados apresentados por Bourdieu (2011) no seu célebre A distinção. Quando o pesquisador despreza as dissonâncias, corre o risco de definir quadros sociológicos caricaturais.

Por isso, ao destacar as variações interindividuais (dentro do grupo) e intraindividuais (no estoque de disposições dos indivíduos), percebe-se as possibilidades múltiplas de ação,

7 Diz Lahire, referindo-se ao livro Retratos Sociológicos: "A pesquisa que deu origem a esta obra tem um caráter extremamente experimental (grifos do autor). Com efeito, aqui não serão encontrados um tema e um objeto de pesquisa tratados de forma clássica, mas resultados de uma vontade de testar empiricamente a validade e a pertinência relativas aos conceitos de disposição, competência, apetência, transferibilidade, ou de aplicar um dispositivo metodológico inédito para as necessidades dessa reflexividade" (2004, p. 20). 
pensamento, sentimento e crença dos indivíduos, que em uma abordagem "coletivista", correm o risco de serem homogeneizados por conceitos, como o de habitus. As dissonâncias mostram, de certa forma, o funcionamento do mundo social. Os processos de socialização dos indivíduos que vivem em sociedades muito diferenciadas cada vez mais se distanciam de quadros socializadores homogêneos.

Ao longo de sua vida de pesquisador e professor, Lahire, um exemplo de trânsfuga de classe e de portador de disposições ascéticas fortes, em sua empreitada crítica contra e com Bourdieu ${ }^{8}$, vai sedimentando sua proposta, burilando-a. Cremos que Monde pluriel (LAHIRE, 2012) é um livro em que a proposta está bem delineada. Recupera o que foi feito até então e sistematiza o elemento que faltava, ou seja, a elaboração de um modelo de espaço social coerente com sua proposta de sociologia em escala individual e que, forçosamente, deveria se erigir da crítica ao outro conceito basilar de Bourdieu, qual seja, o de "campo".

Com o sentimento de tarefa pronta, Lahire se permite "pensar a unidade das ciências sociais", como sugere o subtítulo do livro, a partir da apresentação de uma fórmula científica unificadora (já falamos dela páginas atrás), derivada de seus esforços teóricos e metodológicos empreendidos até então. Como Lahire já havia, em outros livros, dedicado-se bastante a discutir o primeiro termo da fórmula (disposições/passado incorporado), nesta obra debruçar-se-á sobre o segundo termo (os contextos pertinentes de ação). Em pauta, os processos de diferenciação social, típicos das sociedades diferenciadas, que vão colocar em xeque os limites do conceito de campo, apontando como vivem os atores plurais em sociedades diferenciadas. O mundo plural não se remete simplesmente às sociedades diferenciadas de maneira abstrata; do conjunto da reflexão apresentada no livro, tornava-se necessário apresentar um modelo de espaço social ${ }^{9}$ que englobasse, mas, ao mesmo tempo, pudesse se projetar para além do modelo apresentado por Bourdieu, para quem a onipresença do campo é fundamental ${ }^{10}$.

Para Lahire, o macrocosmo social, além dos elementos já conhecidos (campo, classe social), engloba vários domínios, mundos, jogo, quadros de interação, instituições, microgrupos, idades, sexo etc. Todos eles importantes para a compreensão das interações que ocorrem entre os indivíduos. Sendo, porém, fundamental perceber que nas sociedades diferenciadas, nem todos esses elementos podem ser mobilizados ao mesmo tempo para determinada explicação.

Assim, os indivíduos nem sempre estarão inseridos em um campo, pertencerão a uma empresa, um microgrupo, ou estarão isolados em uma classe social. O modelo de espaço social

8 Apesar de Lahire se focar significativamente no pensamento de Bourdieu, isto não deve ser lido de forma restritiva. Lahire é um autor de vasta erudição, que transita por várias áreas do conhecimento. E sua crítica é bastante ampliada não só para autores das ciências sociais, espraia-se para filosofia, literatura, artes, linguística, psicologia, neurociências e, bem destacadamente, para a psicanálise.

9 Para uma leitura esquemática do modelo de espaço social global apresentado por Lahire, ver o adendo do livro Monde pluriel, páginas 353 a 367. Cabe aqui um elogio a forma clara, objetiva e didática da escrita de Lahire. A utilização de recursos, como esquemas, ilustrações, adendos, post-scriptum em seus livros, é uma qualidade a ser apreciada.

10 Para Lahire, habitus e campo não passam de "casos particulares do possível” (LAHIRE, 2012, p. 40). 
global, apresentado por Lahire, é extremamente dinâmico. A nosso ver, bem coerente com a teoria do homem plural e os delineamentos da sociologia em escala individual (disposicionalista e contextualista).

É necessário frisar que, apesar de termos destacado alguns livros de Lahire, aos quais nos referimos como programáticos, todos os outros também têm papel instituinte na proposta de Lahire, sem mencionar os inúmeros artigos e capítulos de livros publicados pelo mundo afora. Sabemos que aqui não é o lugar para se comentar detalhadamente esses livros, pois fugiríamos do objetivo da apresentação do dossiê. Contudo, queremos ao menos registrar o caso da biografia sociológica de Kafka (LAHIRE, 2010), como um dos exemplos importantes de exercício da sociologia em escala individual. Tanto esse livro quanto o mais recente, L'interpretation sociologique des rêves (LAHIRE, 2018), são prova robusta, instigante e de grande fôlego de exercício teórico e metodológico dentro da sociologia em escala individual.

Lahire começa o livro, Franz Kafka: éléments pour une théorie de la création lettéraire, perguntando-se sobre o porquê de Kafka ter escrito o que escreveu e da maneira como escreveu. No coração do livro, diz ele, estão o processo de criação literária e as obras produzidas. Significa que ele se coloca a tarefa de examinar a fabricação social muito precisa do escritor, desde as primeiras experiências familiares até os problemas mais tardios vividos por Kafka. Trata-se de elaborar a sua biografia sociológica, traçando os diferentes quadros de socialização por quais passou e as diferentes experiências que alimentaram seu estoque de disposições ${ }^{11}$. E faz esse processo por etapa.

No primeiro momento, regula o zoom de sua objetiva de maneira a apreender um plano panorâmico da situação econômica, política, cultural e linguística que se impõe a Kafka como a todos os seus contemporâneos. Em seguida, regula a lente para captar cenários menos gerais, planos médios ou quadros mais restritos (geração, grupo familiar, meio escolar, círculo de amigos etc.), nos quais Kafka se situou e, por último, a lente se aproxima ao máximo de Kafka para apreender as lógicas mentais e comportamentais que lhes são próprias (LAHIRE, 2010). O que temos aqui é um deslocamento da lente do "social desdobrado" para o "social dobrado". E vale dizer que não se trata simplesmente da "lógica descendente" da qual falamos no começo deste texto. A chave para a resposta às perguntas colocadas por Lahire sobre Kafka não está dada de antemão nos macroplanos sociais, ou no social desdobrado ${ }^{12}$, tampouco podemos encontrála nas escolhas e reflexividade do autor.

A biografia sociológica, tal como Lahire a compõe, representa movimentar-se incessantemente no caminho (ou como sugerimos, no continuum) que se estende entre disposições e contextos. Se assim não o fizesse, dificilmente poderia ter encontrado a

11 É possível perceber aproximações entre esta obra de Lahire e o livro de Elias sobre Mozart (ELIAS, 1995). 12 Segundo Corcuff (2017), esse foi um erro cometido por Bourdieu no estudo que fez sobre Heidegger (BOURDIEU, 1989). 
"problemática existencial"13 do escritor como elemento crucial para se entender o processo de criação e as obras produzidas por Kafka. Como já dissemos, tanto o livro sobre Kafka quanto o livro sobre os sonhos são exemplos instrutivos do que é e de como funciona a sociologia em escala individual ou sociologia disposicionalista-contextualista.

Ela aparece no contexto brasileiro a partir da década de 1990. O livro Sucesso escolar nos meios populares: as razões do improvável (LAHIRE, 1997) foi o arauto para a recepção das ideias de Lahire em solo nacional. Acolhidas primeiramente no campo da educação, essas ideias gradativamente foram se difundindo para as outras áreas. Daí pra frente, várias obras do autor serão publicadas em português.

Lahire vai se popularizando e se tornando reconhecido como um dos nomes importantes da sociologia contemporânea. Hoje, não são raros os programas de pós-graduação em Sociologia que incluem a sociologia em escala individual como conteúdo das disciplinas de teorias sociológicas, além de se registrar vários trabalhos de pesquisa, em andamento ou concluídos, no formato de dissertações e teses, voltados para o programa teórico-metodológico do autor. Isso se deve não somente ao valor intrínseco do pensamento do autor, mas também aos esforços de colaboração que estão sendo mantidos com ele. Mas, como todo grande autor, sua receptividade não se dá apenas consensualmente. Críticas serão sempre registradas, o que é salutar para o avanço do conhecimento científico.

Nesta última década, os laços de afinidade entre as ideias do autor e as investigações de cientistas sociais foram se estreitando, fortalecidos pela presença do próprio autor, que tem frequentado a comunidade científica brasileira, ministrando disciplinas, palestras, concedendo inúmeras entrevistas e realizando oficinas metodológicas, além de receber em Lyon, professores e alunos, supervisionando-os e orientando-os, em missão de doutorado e pós-doutorado.

Com o intuito de dar evidência e criar redes, divulgar e colocar em pauta questões relacionadas às sociologias do indivíduo, e mais especialmente à sociologia em escala individual de Lahire, é que propomos este dossiê. Nele, trazemos contribuições de autores que já há algum tempo estão ligados às sociologias do indivíduo, ao pensamento disposicionalista e à sociologia em escala individual. Procuramos reunir, ao mesmo tempo, artigos que, por um lado, refletem de forma ensaística as bases que fundamentam essas novas abordagens e, por outro, tomam os postulados teóricos como base, procurando aplicá-los em investigações empíricas, valendose, por exemplo, da metodologia de retratos sociológicos/biografias sociológicas ou de sua adaptação aos problemas investigados em diálogo com novas reflexões e contextos.

Nesse sentido, oferecemos aos leitores, iniciantes e iniciados, elementos necessários para adentrar no campo em questão de forma producente. Montamos o corpus do dossiê com onze peças: um texto de apresentação de autoria dos organizadores, sete artigos de pesquisadores e

13 A expressão designa “o conjunto de elementos ligados à situação social de um autor e que se impõe a ele como questões incontornáveis, que o obcecam, como problemas que tem que enfrentar" (LAHIRE, 2010, p. 111). Lahire propõe que a problemática existencial está direcionada diretamente ao que é a obra e ao trabalho de sua produção. Está na origem do desejo de escrevê-la, é a matriz de produção da obra. 
estudiosos, filiados a universidades brasileiras, uma entrevista com um sociólogo de renome da nova geração de cientistas sociais brasileiros, a tradução de um texto de referência, inédito em língua portuguesa, de autoria de uma das principais referências das sociologias do indivíduo, e finalizando, a resenha do mais recente livro produzido por Lahire.

Abrindo o dossiê, o ensaio da professora Lilia Junqueira, Abordagens biográficas de pesquisa e disposicionalismo sociológico empreende uma reflexão perspicaz sobre as ideias de alguns autores, a respeito dos suportes teóricos e metodológicos que colocam a biografia como importante instrumento para as abordagens disposicionalistas. Toma como referência o texto de Bourdieu - A ilusão biográfica -, tido como um divisor de águas, pois coloca em suspeição a própria validade da biografia como método. A autora coloca em tela autores como Halbwachs, Bourdieu, Passeron e Elias até chegar a Lahire.

Localiza a origem da biografia na Grécia antiga, nas bios, uma espécie de texto/narrativa que elogiava as personalidades nacionais, diz-nos que a noção de biografia nasceu junto com a História. As grandes ressignificações no uso das biografias ocorrem no século XIX, mas, somente no XX, tornam-se função de biógrafos especializados. Na modernidade, a biografia se fortalece com o incremento do individualismo. O interesse de transformá-la em método pelas ciências humanas e sociais se desenvolve no século XX, expandindo-se e diversificando-se.

Há inúmeros complicadores epistemológicos na abordagem biográfica, e para compreendermos como as diversas abordagens usam a biografia, nos alerta a autora, é preciso compreender o estatuto do sujeito que cada uma delas engloba. Analisando o artigo de Bourdieu, com uma potente lente, a autora retira dele as três orientações necessárias para se operar de forma consciente o uso das biografias e para daí encetar um diálogo entre estes dois expoentes da sociologia disposicionalista que são Bourdieu e Lahire. Este último, partindo desses elementos, realiza seus desdobramentos críticos produzindo uma ressignificação positiva, valendo-se da investigação de trajetórias de vida de maneira original, ao propor a superação da ideia da "ilusão biográfica”, entre outras inovações.

No segundo artigo, Ricardo Visser questiona: como repensar uma teoria de classes à luz de uma sociologia disposicionalista? No artigo Sociologia disposicionalista e classes sociais: reflexões sobre desigualdades, toma como suporte, por um lado, a trajetória familiar de classe e de processos de socialização sistêmicos, apoiando-se nos conceitos de habitus e campo de Bourdieu, e, por outro, enfatiza a socialização mais ou menos heterogênea do indivíduo, a partir das variações intraindividuais decorrentes das influências dos diferentes contextos de socialização, ao gosto de Lahire.

Ricardo Visser problematizou a relação entre a formação das classes sociais e os processos de socialização dos atores, a ligação entre origem familiar de classe e as variações intraindividuais e a tentativa de se elaborar uma conciliação teórica entre diferenciação e desigualdade com Bourdieu e Luhmann. O artigo nos leva a uma reflexão sobre os estudos da sociologia disposicionalista para compreender as desigualdades e a teoria de classes sociais, 
quando coloca frente a frente a tese da variação intraindividual e da multidimensionalidade sistêmica da desigualdade e o modelo baseado na origem familiar de classe.

O terceiro artigo: Da periferia à universidade: sucesso escolar e qualidade de vida de jovens de classe popular nos presenteia, logo em seu início, com um precioso mapa da interiorização das universidades públicas no Brasil. Um tema atual e pertinente para ser trazido à tona neste momento da história política brasileira, no qual essa instituição de ensino tem sido atingida por profundos cortes nas verbas que estimulam as atividades de ensino, pesquisa e extensão. $\mathrm{O}$ que vai de encontro às prioridades de governos anteriores que impulsionaram, como o próprio artigo mostra, a interiorização das universidades para dar acesso ao indivíduo que pretender adquirir capital cultural no ensino superior, mas que não tem condição de migrar para estudar nos grandes centros urbanos.

Patrícia Bandeira de Melo e Nathielly Darcy Ribeiro Araújo apresentam o resultado de uma pesquisa, feita a partir do programa de uma sociologia em escala do indivíduo, com perfis sociológicos de estudantes de classes mais populares que, só conseguiram entrar em uma universidade pública por meio da implantação dos campi do ensino superior no interior, tomando como exemplo o Centro Acadêmico de Vitória de Santão Antão, da Universidade Federal de Pernambuco, situado na Zona da Mata daquele Estado.

As autoras mostram, com pertinência teórica e metodológica, que investigar o indivíduo, considerando as diferentes escalas do social introjetado, possibilita mostrar os aspectos da heterogeneidade e da homogeneidade do patrimônio disposicional plural do ator. Ao sinalizar para um diálogo possível entre Lahire e Bourdieu, o artigo aborda os conceitos de habitus, campo e gosto, apresentando o impacto social que o acesso ao ensino superior provoca no processo contínuo de socialização familiar e na legitimação do capital cultural. Ele relata o sucesso escolar dos egressos de universidades públicas do interior e se converte em um bom exemplo do que Bourdieu já defendia: a sociologia é um esporte de combate, pois todo pesquisador tem como missão provocar a reflexão.

Como o conceito de identidade pode ser descortinado do ponto de vista de uma sociologia em escala individual e revelar todas as disposições de um casal na construção simbólica do nome de sua filha? É o que iremos descobrir no quarto artigo: O social habita nos detalhes: a escolha do nome próprio no âmbito de uma sociologia empírica dos afetos. Priscila de Oliveira Coutinho cria as condições de possibilidades para que possamos mergulhar no subterrâneo de uma sociologia dos afetos a partir de uma pesquisa empírica de fôlego, elaborada para contar a história real de uma mulher chamada Juscelina.

Com um olhar meticuloso, a autora, ancorada no postulado teórico e metodológico de Lahire, apresenta-nos uma sociobiografia que conta a história de uma migrante nordestina, filha de pequenos agricultores, que faz a vida no "Sudeste Maravilha" e retorna ao Estado da Paraíba como uma mulher bem-sucedida. Poderia ser enredo de romance ou um gancho para uma reportagem jornalística especial, mas é uma pesquisa sociológica que lembra a política 
de combate à seca do Nordeste, narra a luta do pequeno agricultor para ganhar a vida, cruza o fenômeno social das migrações e perpassa a história de uma família que poderia ser igual a tantas outras, mas não é.

Coutinho trabalha a sociologia empírica dos afetos no seu limite, começando pela relação familiar entre pai e filha, a mais nova dos 19 filhos de seu Gabriel, que recebeu o nome em homenagem ao ex-presidente Juscelino Kubitschek. A autora nos mostra que é possível construir uma tese a partir da sociobiografia de uma pessoa. Assim, somos apresentados a Juscelina e, por que não dizer (?), a muitas Juscelinas que estão nas disposições sociais, não só da biografada como nas de tantas outras mulheres nordestinas.

A partir de uma pesquisa realizada na periferia da Região Metropolitana do Recife, Ana Rodrigues Cavalcanti Alves discute, no quinto artigo: Considerações sobre as práticas de consumo das classes populares a partir de uma sociologia disposicionalista, as condições que propiciaram a incorporação de novas inclinações e propensões para o consumo entre indivíduos situados em frações ascendentes das camadas populares brasileiras. A autora parte de uma noção de classe social que funciona não como pressuposto, mas como resultado final de uma atitude indutivamente referida sobre a realidade social concreta investigada, reconstruindo sociologicamente os indivíduos pertencentes às classes populares sobre os quais lança seu olhar.

Por meio de uma leitura crítica e criativa do estruturalismo gerativo de Pierre Bourdieu, da teoria do ator plural de Bernard Lahire e da teoria das classes sociais de Jessé Souza, a autora apresenta uma reflexão teórico-metodológica inovadora sobre os estilos de vida dos indivíduos das classes populares que lhe permite questionar as visões mais generalistas que tendem a definir esse universo por meio da acentuação apenas de um comportamento ascético em relação ao mundo.

Considerando que, de fato, tal dimensão é importante, mas não a única existente nas classes populares, com base em dados obtidos com entrevistas em profundidade, a socióloga identifica diferentes tipos de ethos coexistindo nesta camada da sociedade, engendrados diferencialmente pela incorporação de complexas e específicas combinações de disposições para a prática.

Dessa forma, por um lado, é possível refletir sobre "batalhadores ascéticos", produzidos socialmente por meio de uma trajetória ascendente marcada por experiências contínuas definidas pela ética do trabalho duro, em cujo percurso incorporaram propriedades imanentes de condições materiais e temporais urgentes. Assim, suas práticas de consumo tendem a se voltar para a esfera doméstica, na medida em que se associam fortemente a um tipo de moralidade fundada em valores que visam oferecer conforto ao grupo familiar.

Por outro lado, os indivíduos hedonistas das classes populares, embora também marcados por experiências ancoradas numa ética do trabalho duro, vivenciam o âmbito do consumo de maneira distinta dos portadores de um ethos ascético. Nesse caso, suas práticas de consumo são 
acompanhadas por uma "retórica do desejo e do querer", possibilitada por uma constituição disposicional complexa e plural, estabelecida em processos de socialização heterogêneos em que as dimensões individuais ganham força, condicionando a uma maior valorização de um estilo de vida que valoriza aspirações e expectativas individuais legitimadas por uma cultura de consumo moderna.

No sexto artigo, Retratos sociológicos do maracatu de baque solto: percursos, disposições, práticas e variações culturais, José Roberto Sena coloca em foco a cultura popular a partir da lente da sociologia em escala individual, apresentando-nos a sociobiografia de um jovem contra/ mestre de maracatu de baque solto da cidade do Recife. Utilizando-se dos dispositivos teóricos e metodológicos propostos por Lahire, enriquecidos por conhecimentos que obteve durante estada na Universidade do Porto, junto a sociólogos portugueses de inspiração disposicionalista e contextualista, o autor pretende ir além dos estudos sobre o maracatu que "se limitam a tentar compreender as histórias e/ou o contexto sociocultural dos grupos." Alega que eles têm se limitado aos aspectos estruturais e grupais, sendo que as poucas pesquisas em escala biográfica existentes "não se aprofundaram nas variações inter e intraindividuais dos praticantes, mas sim, reafirmaram o protagonismo típico-ideal dentro de um campo delimitado".

O retrato sociológico apresentado por José Roberto busca nos revelar, focando-se na trajetória desse jovem, outra imagem dos grupos de maracatu: um quadro de atores plurais que não se restringem a ser maracatuzeiros, são pluralidades que transitam por muitos contextos, sofrendo múltiplas pressões e possibilidades. O artigo nos leva a perceber a trajetória múltipla e tensa do indivíduo, pontuando não só como as disposições são criadas, ativadas ou inibidas pelos contextos, mas também as variações e heterogeneidades culturais, a distinção de si contra si, os antagonismos envolvidos na condição de ser maracatuzeiro.

O desfecho da história nos leva a refletir sobre como se cruzam as trajetórias individuais e as coletivas: o jovem contra/mestre encontra-se dividido entre suas novas crenças religiosas e o maracatu. Tudo indica que se decidirá pela religião e, ao fazê-lo, tenderá a abandonar o maracatu. Somos tentados a imaginar como a saída do grupo, e do que ele articula e representa, poderá reconfigurar as "feições" do próprio ator e dos demais que compõem o grupo.

O último artigo, Pensar com Lahire e Bourdieu: disposições sociais e gostos de elite no Recife, aborda um tema que desperta interesse imediato: a construção do "gosto" a partir do olhar disposicionalista. Louise Claudino Maciel propõe, assim, analisar os sistemas de preferências e de aversões de indivíduos de diferentes classes da Região Metropolitana do Recife no campo da decoração, abordando os aspectos que aproximam e distanciam Bourdieu e Lahire no desenvolvimento de uma sociologia das disposições.

O trabalho empírico, objeto de uma pesquisa de doutoramento, toma como lastro uma seção sobre decoração de uma revista chamada Aurora, publicada pelo Diário de Pernambuco, o jornal impresso mais antigo em circulação na América Latina, entre 2011 e 2014. 
A partir daquela seção, a pesquisadora realizou 20 entrevistas em profundidade, como parte do trabalho etnográfico. Nele, elaborou duas categorias analíticas das práticas sociais manifestadas na decoração: o gosto burguês e o gosto intelectual. No artigo, são apresentados perfis culturais construídos, levando em consideração o capital cultural que reproduz a posição que os entrevistados ocupam no espaço social do Recife.

Ainda como parte do dossiê, temos $O$ indivíduo, a existência e a teoria social: uma entrevista com Frédéric Vandenberghe. Realizada por Rodrigo Vieira de Assis durante o $42^{\circ}$ Encontro Anual da Anpocs, a entrevista explora o amplo leque de conhecimento que Frédéric Vandenberghe, professor do Programa de Pós-graduação em Sociologia e Antropologia da Universidade Federal do Rio de Janeiro (PPGSA/UFRJ), tem a oferecer quando o assunto é a teoria social contemporânea. Sociólogo belga radicado no Brasil, Vandenberghe transitou por diferentes contextos internacionais de produção sociológica, circulação que lhe permite discorrer com naturalidade sobre temas tão diversos quanto o indivíduo na teoria sociológica clássica, a emergência das teorias da modernidade na Inglaterra e a consolidação das sociologias do indivíduo na França, sem perder de vista a sua própria trajetória dentro do campo sociológico internacional.

Nesse sentido, esses e outros eixos temáticos são discutidos ao mesmo tempo em que o percurso de formação acadêmica de Vandenberghe - iniciado na Bélgica, passando pela França, Inglaterra, EUA e Alemanha - é descortinado. Em virtude das mudanças contextuais a que esteve sujeito, explora-se aqui a produção teórica intensa e eclética, porém inteiramente coerente, do sociólogo, que pode ser compreendida no trânsito de ênfases consecutivamente realizados no âmbito da teoria crítica, da fenomenologia e do realismo crítico.

Porém, sem se reduzir a nenhuma dessas três vertentes em si mesmas, mas influenciado por autores como Peter Berger, Pierre Bourdieu, Anthony Giddens, Jügen Habermas e Jeffrey Alexander, Vandenberghe deixa transparecer os fios constitutivos do seu próprio pensamento, cuja complexidade lhe permite decifrar e reconstruir inúmeros edifícios teóricos, como se pode verificar em seus inúmeros trabalhos já publicados, referenciados ao longo da entrevista aqui especialmente disponibilizada ao público de Política \& Trabalho.

Nesse sentido, podemos dizer, como o faz Vieira de Assis durante a entrevista, que Frédéric Vandenberghe constrói a sua própria teoria por meio de uma atitude intelectual que faz lembrar o trabalho de um arquiteto, cujo olhar treinado é capaz de identificar e articular as estruturas e as bases de sustentação de teorias sociais e sociológicas diversas. Não por acaso, ao tratar especificamente do indivíduo na teoria sociológica, são identificadas controvérsias em torno da definição dessa importante categoria, além de equívocos em algumas das argumentações daqueles que são os principais representantes do trabalho sociológico dedicado ao estudo sistemático das dimensões individuais na contemporaneidade.

Sem dúvida, o rico material obtido nesse diálogo, pela primeira vez publicado, traz consigo elementos para se pensar não só a sociologia em si mesma, mas, muito além disso, 
refletir sobre as possibilidades de as teorias alcançarem as dimensões sutis da vida social, talvez inacessíveis à racionalidade científica que hoje temos, que é a própria condição existencial que nos define profundamente. Nesses termos, seguindo a posição de Vandenberghe, precisamos questionar, diante de tudo o que nos acomete no presente, para onde vai a sociologia e o que ela é ainda capaz de nos oferecer ao estarmos, todos, dentro de uma locomotiva desgovernada, cujos trilhos foram retirados de seu caminho, embora sigamos, sem saber exatamente para que direção, em seu interior.

O dossiê conta também com a tradução do artigo As individualidades populares: análise de setores urbanos no Chile, de Kathya Araujo e Danilo Martuccelli. Importantes referências no conjunto de autores dedicados à elaboração de abordagens sociológicas capazes de examinar as dimensões individuais e, por meio delas, identificar os modos de singularização do social, Araujo e Martuccelli apresentam neste texto os resultados de uma pesquisa empírica realizada com indivíduos situados nas camadas populares chilenas. Recorrendo a dados oriundos de entrevistas semiestruturadas e grupos focais compostos por pessoas atuantes em ocupações de baixo prestígio social, são discutidas e identificadas as individualidades populares, concebidas como propriedades e inclinações imanentes de uma relação muito particular estabelecida entre os indivíduos e a sociedade em que se veem implicados.

Nesse sentido, sem aderir à sociologia em escala individual de Bernard Lahire, mas sugerindo outra perspectiva sociológica capaz de apreender e destrinchar o social nos indivíduos, Araujo e Martuccelli propõem uma leitura que tem como base o conceito de imaginação sociológica de Charles Wright Mills, através do qual é possível reconectar existências individuais às estruturas sociais que os interpelam. Nesses termos, as individualidades populares emergem como resultado de existências estruturais a que todos os indivíduos, numa mesma época histórica, estão sujeitos.

Se inicialmente isto parece apontar para uma ênfase no constrangimento da agência humana, os leitores perceberão que os autores, de maneira muito sensível, chamam a atenção para a capacidade que os indivíduos constituídos em camadas menos privilegiadas têm para se disporem a enfrentar as condições que a eles se impõem de maneira muitas vezes surpreendente: como uma condução da vida com leveza em meio a adversidades e aprendendo a aproveitar as oportunidades que a eles se apresentam na vida cotidiana, para usar dois aspectos desenvolvidos no artigo.

Assim, desenvolvendo o argumento em várias etapas, Araujo e Martuccelli exploram, nesse artigo, aspectos especialmente interessantes no nível individual, correlacionando-os sempre a dimensões estruturais, como o que passam a chamar de "a força do caráter", "a habilidade e o sentido de oportunidade" e "o prazer e a irreverência humorística". Os autores trazem discussões teóricas e metodológicas desenvolvidas no Chile que, de modo algum, restringem-se à realidade daquele país, mas são capazes de nos levar a refletir sobre nosso próprio contexto. 
Fechando o dossiê, Giovanni Boaes e Maylle Alves Benício nos trazem o texto "Um sonho para as ciências sociais" ${ }^{14}$, resenha da mais recente publicação bibliográfica de Bernard Lahire. O livro L'interpretation sociologique des rêves foi publicado em 2018, ainda sem tradução para o português, e representa o resultado do esforço do autor de mais de vinte anos de aprofundamento sobre as ciências do sonho. Como uma de suas marcas, Lahire abre o livro, colocando-se questões : "O que podem dizer os sonhos sobre a vida dos indivíduo e das sociedades em que vivem?" "Como as experiências sociais dos 'sonhadores' contribuem para tramar seu imaginário, mesmo nos momentos quando a consciência intencional não governa o fluxo das imagens?”

Atentos a esses questionamentos, os autores da resenha, empreendem uma leitura pormenorizada da obra, acompanhando a aventura sociológica de Lahire em "terra incógnita" da expressão onírica. Veem-no estender o alcance da sociologia disposicionalista e contextualista da ação àquilo que parece ser o mais recôndito do psiquismo humano, o "inconsciente", para demonstrar sua face social, traduzido como um tipo específico de consciência - uma "consciência involuntária" - representada pelo passado incorporado na forma de esquemas de disposições. Destacam que, se em outras obras, o papel da crítica contra e com Bourdieu esteve fortemente presente, neste livro, a contenda principal se dá com e contra a psicanálise, mais precisamente, voltada para a figura do seu fundador, Sigmund Freud.

Fecham a resenha, reconhecendo que a obra representa um marco no conjunto da obra de Lahire, por trazer possibilidades de reformulações acerca de sua fórmula geral das práticas. Enfim, como o próprio autor destaca, e é bem percebido pelos autores da resenha, para a sociologia estudar o sonho no que ele tem de específico, ou seja, como uma forma de expressão humana, ela será levada necessariamente a se transformar, rever suas formulações teóricas e seus modelos metodológicos, tarefa que a sociologia em escala individual e todas as sociologias do indivíduo já vêm desempenhando há algumas décadas.

Cabe aos organizadores, nestas últimas linhas, desejar que os leitores possam tirar proveito dos textos contidos neste dossiê.

\section{Referências}

ALEXANDER, Jeffrey. O novo movimento teórico. Revista Brasileira de Ciências Sociais, São Paulo, v. 2, n. 4, p. 6-28, jun. 1987. Disponível em: http://www.anpocs.org.br/portal/publicacoes/rbcs_00_04/rbcs04_01.htm. Acesso em: 05 maio 2019.

BOURDIEU, Pierre. A distinção: crítica social do julgamento. Porto Alegre: Zouk, 2011.

Ontologia política de Martin Heidegger. Campinas: Papirus, 1989.

CORCUFF, P. O coletivo ante o desafio do singular: falando sobre habitus. In: VISSER, R; JUNQUEIRA, L. (org.). Dossiê Bernard Lahire. Belo Horizonte: Editora da UFMG, 2017, p. 169-200.

14 Os autores utilizam o mesmo título da introdução do livro, considerando o efeito de sentido que gera, ao referir-se ao "projeto", não só de Lahire mas de outros cientistas sociais, em transformar o sonho em objeto destas ciências. 
ELIAS, Norbert. Mozart: sociologia de um gênio. Rio de Janeiro: Zahar, 1995.

GAULEJAC, Vincent de. O âmago da discussão: da sociologia do indivíduo à sociologia do sujeito. Cronos, Natal-RN, v. 5/6, n. 1/2, p. 59-77, jan./dez. 2004/2005. Disponível em: https://periodicos.ufrn.br/cronos/article/ view/3233. Acesso em: 05 mai. 2019.

KAUFMANN, Jean-Claude. Ego: para uma sociologia do indivíduo. Lisboa: Instituto Piaget, 2001.

LAHIRE, Bernard. O homem plural: as molas da acção. Lisboa: Instituto Piaget, 2001.

LAHIRE, Bernard. A cultura dos indivíduos. Porto Alegre: Artmed, 2006.

LAHIRE, Bernard. Franz Kafka: éléments pour une théorie de la création lettéraire. Paris : La Découverte, 2010.

LAHIRE, Bernard. L'interpretation sociologique des rêves. Paris: La Découverte, 2018.

LAHIRE, Bernard. Monde pluriel: penser l'unité des sciences sociales. Paris: Editions du Seuil, 2012.

LAHIRE, Bernard. Retratos sociológicos: disposições e variações individuais. Porto alegre: Artmed, 2004.

LAHIRE, Bernard. Sucesso escolar nos meios populares: as razões do improvável. São Paulo: Ática, 1997.

MARTUCCELLI, D. Lecciones de sociología del individuo. Lima: Pontificia Universidad Católica del Peru/ Departamento de Ciencias Sociales, 2007. Disponível em: http://repositorio.pucp.edu.pe/index/bitstream/handle/123456789/52674/lecciones_sociolog\%C3\%ADa_martuccelli.pdf?sequence=1\&isAllowed=y. Acesso em: 05 mai. 2019.

Recebido em: 18/05/2019

Aceito em: 18/05/2019 